\title{
1 A new reconstruction of atmospheric gaseous elemental 2 mercury trend over the last 60 years from Greenland firn \\ 3 records
}

4 A. Dommergue ${ }^{1}$, P. Martinerie ${ }^{1}$, J. Courteaud ${ }^{1}$, E. Witrant ${ }^{2}$, D. M. Etheridge ${ }^{3}$

5 [1] Univ. Grenoble Alpes/CNRS, Laboratoire de Glaciologie et Géophysique de

6 l'Environnement (LGGE) UMR 5183, Grenoble, F-38041, France

7 [2] Univ. Grenoble Alpes/CNRS, Grenoble Image Parole Signal Automatique (GIPSA-lab), 8 UMR 5216, B.P. 46, F-38402 St Martin d'Hères, France

9 [3] CSIRO Oceans and Atmosphere, 107-121 Station St., Aspendale, Victoria 3195, 10 Australia

11 Correspondence to: Aurélien Dommergue (aurelien.dommergue@univ-grenoble-alpes.fr)

12 Abstract

13 This study presents measurements of gaseous elemental mercury (GEM) concentrations in the 1480 meters of firn air at the international drilling site of NEEM in Greenland $\left(2452 \mathrm{~m}, 77^{\circ} 25.8\right.$ $\mathrm{N}, 51^{\circ} 06.4 \mathrm{~W}$ ). Using inverse modeling, we were able to reconstruct the atmospheric GEM trend at this Arctic site over the last 60 years. We show discrepancies between this record and the previous firn record of Summit. This could be attributed to experimental biases and/or differences in air mass transport. A multisite inverse model was used to derive an atmospheric scenario reconciling the two firn records. We show that GEM seasonal variations are very limited at these high altitude sites and thus probably unaffected by spring/summer photochemistry. The firn reconstructions suggest an increase of GEM concentrations since the 1950s peaking in the late 1960s and early 1970s. A decrease is then observed with minimum GEM concentrations around 1995-2000. The reconstruction compares well with historical mercury $(\mathrm{Hg}$ ) releases and recent simulations of atmospheric $\mathrm{Hg}$. Our optimal GEM scenario does not allow to categorically conclude on recent trends for GEM concentrations over the 2000-2010 decade. 


\section{Introduction}

The Arctic troposphere receives mercury $(\mathrm{Hg})$ through air mass transporting anthropogenic emissions (mining, fuel combustions) from Asian, Northern American and European sources (Durnford et al., 2010). Hg mainly reaches the arctic troposphere as gaseous elemental mercury (GEM), as it has a longer atmospheric lifetime than other Hg species. GEM is also emitted by evasion from the Arctic Ocean (Dastoor and Durnford, 2013) and by re-emission of deposited $\mathrm{Hg}$ from snow and ice surfaces (Durnford and Dastoor, 2011). The oceanic $\mathrm{Hg}$ source, fed by circumpolar riverine inputs, was recently shown to dominate at coastal Arctic sites, where it could cause a summertime atmospheric GEM maximum (Fisher et al., 2012).

Atmospheric GEM concentrations in the Arctic troposphere are one of the key parameters that controls $\mathrm{Hg}$ deposition. How the Arctic atmosphere responded to historical changes in anthropogenic emissions is an important question to answer in order to understand the present-day biogeochemical cycle of $\mathrm{Hg}$ in the Arctic. This understanding is also a prerequisite for predicting how the $\mathrm{Hg}$ cycle will be affected by future $\mathrm{Hg}$ emission policies (e.g. the Minamata Convention).

The longest monitoring record of atmospheric GEM in the Arctic began in 1995 at Alert $\left(82^{\circ} \mathrm{N}\right.$, Canada) and revealed important seasonal variations (Cole and Steffen, 2010; Steffen et al., 2008). The High Arctic springtime atmosphere is characterized by extremely low GEM values $\left(<1 \mathrm{ng} . \mathrm{m}^{-3}\right)$ due to a photochemically-driven rapid oxidation process involving bromine, while summer months exhibit a return to higher GEM values $\left(\sim 2 \mathrm{ng} \cdot \mathrm{m}^{-3}\right)$. The socalled springtime atmospheric mercury depletion events (AMDE) are an important pathway by which atmospheric GEM can be converted into more labile species (Larose et al., 2011). It delivers large quantities of oxidized mercury $(\mathrm{Hg}(\mathrm{II}))$ on environmental surfaces for a short period of time (Douglas et al., 2012). $\mathrm{Hg}$ (II) species are susceptible to photoreduction and a fraction - which is large in the case of seasonal terrestrial snowpacks - is rapidly reemitted back to the atmosphere as GEM (Poulain et al., 2004). The air monitoring records at Alert and at Zeppelin station $\left(79^{\circ} \mathrm{N}\right.$, Svalbard) show either slowly declining or stable GEM levels in the past decade (Berg et al., 2008; Berg et al., 2013; Cole and Steffen, 2010; Cole et al., 2013). These observations, as well as others from sub-Arctic sites (Cole et al., 2013), appear to contradict rising global Hg emission trends (Streets et al., 2011). However, recent modeling studies have highlighted the potentially important role played by the ocean (Chen et al., 2015; Soerensen et al., 2012) in modulating atmospheric GEM levels (Fisher et al., 2013). 
1 An indirect method to reconstruct long-term trends in atmospheric gases consists of

2 measuring their concentration profile in the interstitial air (also called firn air) of the upper

3 layers of polar ice sheets (e.g. Schwander et al., 1993; Witrant et al., 2012). Applying this

4 method at Summit in central Greenland, Faïn et al. (2009) reconstructed a history of Arctic

5 GEM levels over 60 years. Their measurements revealed that atmospheric GEM concentrations peaked in the 1970s and were in line with global $\mathrm{Hg}$ production. In this paper, we present GEM measurements obtained in the upper $80 \mathrm{~m}$ of the northeastern Greenland ice sheet cap at the international drilling site NEEM (North Greenland Eemian Ice Drilling). Using a new and robust modeling approach, we are able to propose a new atmospheric scenario of GEM for the last 60 years. GEM data obtained at Summit (Faïn et al., 2009) are re-evaluated and compared to our results.

\section{Firn air sampling and GEM analysis}

13 GEM measurements were carried out during the NEEM program from July $16^{\text {th }}$ to July $29^{\text {th }}$, 2009. The NEEM site is situated in northeastern Greenland (Figure 1) at an altitude of 2452 meters above sea level. Experiments were conducted $1.8 \mathrm{~km}$ away from the main camp $\left(77^{\circ} 25.8 \mathrm{~N}, 51^{\circ} 06.4 \mathrm{~W}\right)$.

The sampling of firn air was first documented by Schwander et al. (1993). Here we describe a modified setup for the extraction of large samples using a Firn Air Sampling Device (FASD). Drilling progressed stepwise with sampling at intervals of $10 \mathrm{~m}$ until the beginning of the lock-in zone (at $\sim 60 \mathrm{~m}$, (Buizert et al., 2012)). The lock-in zone is the firn region where air bubbles begin to be trapped in the ice matrix and vertical gas diffusion significantly slows and eventually stops. In the lock-in zone, drilling was made at intervals of 1 to $3 \mathrm{~m}$. At each sampling level the drill was withdrawn and the hole sealed close to the bottom with a $3 \mathrm{~m}$ long inflatable butyl rubber bladder. A pumping system from CSIRO (KNF N286.15 Diaphragm compressor, $15-25 \mathrm{l} / \mathrm{min}$ ) inflated the bladder to $90-150 \mathrm{kPa}$ with air drawn from the firn and monitored its pressure. Two continuous, $100 \mathrm{~m}$ long, 3/8 inch Nylon (type 12; Watsford Tubetech, Nunawading, Victoria, Australia) tubes passed through the bladder, connecting the pumping system at the surface to the bottom of the hole. Sampled air was drawn through both tubes and flasks were filled for later trace gas concentrations and isotopic ratios analysis. The quality of the sampling was checked at each level after inflating the bladder, and at the end of the measurements. $\mathrm{A} \mathrm{CO}_{2}$ analyzer (Sick-Maihak 710) was used to detect possible leaks from the bladder or tubes, and to verify the complete removal of modern 
1 air introduced in the hole when drilling and lowering the bladder. It also provided an

2 indication of the mean age of the air, and whether air flowed from adjacent firn layers (with

3 different ages) during pumping. The variations in $\mathrm{CO}_{2}$ concentrations at each level between

4 measurements were relatively small, typically decreasing by less than $2 \mathrm{ppm}_{\mathrm{v}}$ during sampling at each level, depiste pumping a total air volume of 1000-2000 L.

GEM concentrations in the firn air were measured online. An additional Teflon pump (Vacuumbrand MZ2NT) and the GEM analyzer were connected to the FASD. System components were tested in the lab during construction of the FASD for their effect on GEM, for instance the Nylon tubing, which was found to have no effect. All components were steam cleaned and baked in an oven before assembly. These parts of the system were leak-tested, and several blanks of the FASD line were realized using GEM-free air produced by an activated charcoal cartridge. Two sources of contamination were noticed during blank tests at NEEM before proceeding: a needle valve, which was subsequently removed, and the Nylon tubing when exposed to direct sunlight. Shading the tubing reduced the GEM blanks to below detectable levels. The system used during this campaign did not show any evidence of GEM contamination, while the previous study of Summit (Faïn et al., 2009) had to account for positive blanks, that were subtracted from the measurements. GEM collection and analysis were performed using a 2537A gas phase $\mathrm{Hg}$ analyzer (Tekran ${ }^{\circledR}$ Instruments Corporation). This instrument uses gold-amalgamation, thermal desorption in a pure argon stream and $\mathrm{Hg}$ detection by Atomic Fluorescence Spectrometry (AFS) at $253.7 \mathrm{~nm}$. Two parallel gold cartridges allow alternate sampling and desorption, resulting in continuous measurement of GEM on a pre-defined time base. The analyzer was operated with a 5-min sampling frequency and the pre-filtered $(0.2 \mu \mathrm{m}$ PTFE filters $)$ air was sampled at a flow rate of $1 \mathrm{~L} \cdot \mathrm{min}^{-1}$. At each sampling depth, we continuously measured GEM for at least $55 \mathrm{~min}$ and up to $150 \mathrm{~min}$ depending on the field schedule. GEM concentrations in the firn were very reproducible at a given depth, with a relative standard deviation less than 5\% (except at depth $73 \mathrm{~m}$ and $75 \mathrm{~m}$ where the standard deviations were $9 \%$ and $7 \%$ respectively). The analyzer was calibrated before each measurement using the internal permeation source. An external calibration with $\mathrm{Hg}$ vapor injections was performed in the laboratory before the field work. Under these conditions, the relative uncertainty of the instrument on one measurement was better than 0.1 ng. $\mathrm{m}^{-3}$. 
GEM concentration at two meters above the snow surface were periodically measured during the firn air experiment with a 5-min resolution. After the firn air experiment, continuous atmospheric GEM measurements were made for 6 days providing an estimate of mean surface levels.

\section{Firn air modeling for mercury}

\subsection{Laboratoire de Glaciologie et Géophysique de l'Environnement and Grenoble Image Parole Signal Automatique (LGGE-GIPSA) model}

Firn is an open porosity medium where atmospheric gases move mainly by diffusion. Its density increases from the surface to the firn-ice transition, and the firn diffusivity decreases in consequence. Variations of atmospheric GEM concentrations occurring at the surface propagate into the firn by molecular diffusion, gravitational settling and advection (due to the fact that the firn sinks progressively as snow accumulates). The physics of our model are described in detail in Rommelaere et al. (1997) and Witrant et al. (2012). Model evaluation through an international model comparison is presented in Buizert et al. (2012). Site specific description of firn diffusivity calculations can be found in Witrant et al. (2012) and in Zuiderweg et al. (2013) for Summit and NEEM 2009 respectively. Using in turn the diffusivity profiles tuned to trace gas and gas isotopic measurements at each of the firn air pumping operations performed at NEEM in 2008 and 2009 (Note: GEM measurements are only available for the NEEM 2009 experiment) had no significant influence on the results (see supplementary Figure S4).

Two GEM specific physical constants are used in the gas transport model: its atomic weight $\left(200.59\right.$ g.mol $\left.{ }^{-1}\right)$ and its relative diffusion coefficient in air with respect to $\mathrm{CO}_{2}$. Based on GEM diffusion coefficient measurements (Lugg, 1968; Massman, 1999), $\mathrm{CO}_{2}$ diffusion coefficient measurements (Massman, 1998; Matsunaga et al., 1998) and the calculations from Chen and Othmer (1962) discussed in Buizert et al. (2012), a range of 0.822-0.868 was obtained for the $\mathrm{GEM} / \mathrm{CO}_{2}$ diffusion coefficient ratio. The value of 0.868 derived from Chen and Othmer (1962) is used below, and a sensitivity test using 0.822 had only a small impact on the results (see supplementary Figure S4).

Inverse modeling of gas transport in the firn is required to reconstruct an atmospheric time trend from concentration vertical profiles. It is a mathematically under-determined problem, which means that it has several possible solutions (Rommelaere et al., 1997). We 
use the most recent version of the LGGE-GIPSA model (Witrant and Martinerie, 2013) in which the optimal solution is determined using the cross-validation statistical method. The concentrations are forced to be positive using a log barrier method (Boyd and Vandenberghe, 2004). Imposed positivity of concentrations mostly improves the results for recently emitted anthropogenic compounds with null concentrations in deep firn (e.g. Laube et al., 2014). Recent reconstructions of CO (Petrenko et al., 2013) and light alkanes (Helmig et al., 2014) with the LGGE-GIPSA model are interesting to compare with the present GEM reconstructions because all these datasets show peak shapes in the deep firn, and a good consistency between several Greenland sites was obtained for CO and light alkanes.

\subsection{Age distribution in the firn}

Due to mixing by molecular diffusion, the GEM atoms found at a given depth in the firn have different ages. Using a Dirac function as input, the forward model calculates an age distribution (or Green's function) for a given gas at each depth in the firn (Rommelaere et al., 1997). Table 1 and Figure S1 (Supplementary Information) show the estimated mean age of GEM $( \pm 1 \sigma)$ in the firn at NEEM and Summit. Ages increase slowly in the upper part of the firn, then rapidly in the lock-in zone (where most of air bubbles close) and diffusion effectively ceases. Diffusional smoothing results in increasing gas age distribution with depth, mainly above the lock-in zone. The age distribution stabilizes in the lock-in zone where diffusion becomes negligible and advection with the ice dominates. The overlap between possible gas age distribution at two successive sampling depths (especially in deep firn) implies that GEM measurements are auto-correlated and that the firn acts as low-pass filter. The model interprets irregular concentration variations in firn either as large variations in the atmosphere or as noise. The optimal solution is chosen using a statistical analysis of the signal by a cross-validation method. The depth where closed porosity over total porosity reaches 0.5 is 78.6 meters for Summit and 76 meters for NEEM. It means that $\sim 50 \%$ of the gas becomes unavailable for pumping at these depths because it is trapped in closed bubbles. Mean GEM ages at these depths are 43.6 years for Summit and 67.5 years for NEEM.

\subsection{Hg physico-chemical behavior in the firn}

The calculations of GEM age distributions in the firn presented above and their use to infer past atmospheric GEM variations implicitly assume that GEM concentrations in the firn are not modified by chemical reactions or physical interaction with snow and ice surfaces. 
1 While GEM is weakly adsorbed on ice surfaces (Bartels-Rausch et al., 2008), it can be

2 photochemically produced or oxidized in the seasonal snowpack (Lalonde et al., 2002;

3 Poulain et al., 2004). We cannot rule out that these reactions occur in the NEEM snowpack,

4 but their effects are probably limited to the top layers of the firn. Faïn et al. (2008) showed that in central Greenland, these processes occur only during a limited period in summer. At NEEM, the consistency of GEM concentrations at depths of 20,30 and $40 \mathrm{~m}$ where the air is $<5$ years old (respectively 1.39, 1.34 and 1.39 ng. $\mathrm{m}^{-3}$ ) with the measured mean surface atmospheric GEM concentration $\left(1.38 \pm 0.10 \mathrm{ng} \cdot \mathrm{m}^{-3}, \mathrm{n}=327\right)$ suggests that the influence of near-surface reactions on GEM is limited and within the measurement uncertainty. However, long-term measurements of GEM in the atmosphere and in the snowpack and firn are needed to firmly establish whether near-surface photochemical processes have any significant influence on the GEM signal that is stored in the firn air.

\section{Results}

\subsection{GEM concentrations in firn air and in the atmosphere at NEEM}

GEM concentrations measured at 14 depths in the firn at NEEM are presented in Figure

2. Average GEM concentrations at these depths varied between 0.85 and 1.39 ng.m ${ }^{-3}$ with maximum levels found in the upper layers and between 67 and $73 \mathrm{~m}$. The mean surface atmospheric GEM concentration was $1.38 \pm 0.10 \mathrm{ng} \cdot \mathrm{m}^{-3}(\mathrm{n}=327)$ during the 6 days of sampling. Figure 2 also shows measurements made both in firn air and in the atmosphere at Summit Greenland in 2006 (Faïn et al., 2009).

Due to gravitational settling, gases having a higher atomic or molecular weight than air show enrichment with depth in firn. This effect is enhanced for GEM due to its high atomic weight. It can be illustrated by using a GEM constant concentration as input to the forward firn model. On Figure 2, the (constant) atmospheric concentrations are adjusted in order to fit the upper firn GEM data at Summit and NEEM. For Summit, an atmospheric level of 1.7 $\mathrm{ng} / \mathrm{m}^{3}$ can fit the firn air data within uncertainties down to $66 \mathrm{~m}$ depth (corresponding to gas ages between 1997 and 2006.4). For NEEM, an atmospheric GEM level of $1.38 \mathrm{ng} / \mathrm{m}^{3}$ can fit the firn air data down to $50 \mathrm{~m}$ depth (corresponding to gas ages between 1997 and 2004.5). The consistency of model results with upper firn GEM data at both sites using constant atmospheric concentrations indicates no significant GEM trend over a decade preceding the firn air pumping (see Table 1). 
The low variability of GEM concentrations in the upper 30 meters of the firn also suggests a small seasonal variation for atmospheric GEM. Measurements of atmospheric

3 GEM at Summit made over several weeks in spring and summer, confirm this (Brooks et al., 2011)(Fain et al. personal communication). A large seasonal pattern (such as the one observed at Alert) would induce steep concentration gradients in the upper $30 \mathrm{~m}$ meters of the firn, as observed for CO and light alkanes (e.g. Helmig et al., 2014; Petrenko et al., 2013; Wang et al., 2012). Below $40 \mathrm{~m}$ depth, firn air concentrations reflect an averaging of the atmospheric signal over more than a year due to diffusional mixing.

The different atmospheric mean GEM concentrations $\left(1.7\right.$ versus $\left.1.38 \mathrm{ng} / \mathrm{m}^{3}\right)$ at the two sites however suggest a discrepancy between the two firn air pumping experiments and/or a difference in the air masses reaching those sites.

\subsection{Single site atmospheric scenarios}

Figure 3 shows the optimal inverse model GEM scenarios that result in the fit with the NEEM and Summit firn data, respectively. Different scenarios were tested to find the optimal solution, as discussed in Wang et al. (2012) and these are presented in Figure S2. The root mean square deviations between model results and data $\left(\mathrm{RMSD}_{\text {model-data }}\right)$ for the different scenarios are provided in Table S1. Scenarios with the smoothest GEM variations induced important mismatches between simulated and measured GEM profiles in firn, whereas scenarios with the largest GEM variations required unrealistically large atmospheric variations to match minor features in the data.

The optimal scenarios for Summit and NEEM show similar patterns with an increase of atmospheric GEM concentration after the 1950's and an atmospheric GEM concentration maximum in $\sim 1970$. However, the firn measurements and the single site scenario reconstructions both indicate that there are inconsistencies between the Summit and NEEM datasets. Compared to NEEM, the more pronounced peak shape of the Summit firn air GEM in the 1970s requires larger atmospheric GEM variation in the corresponding optimal scenario. Our optimal scenario for Summit is similar to the one obtained by Faïn et al. (2009) using a Monte-Carlo method, although the 1970 peak amplitude is sensitive to the choice of the inverse model solution (Figure S2). In contrast, the optimal atmospheric GEM scenario inferred from the NEEM firn air suggests only minor atmospheric GEM variations since 1950 when taking into account the experimental uncertainty. 


\subsection{Multi-site scenario reconstructions}

Constraining the atmospheric trend with both Summit and NEEM data sets leads to a poor match of the firn data (see upper panels of Figure 4). Consequently, $\mathrm{RMSD}_{\text {model-data }}$ strongly increases (see Table 2) and leads to a large uncertainty envelope. Simple attempts to reconcile the two records were made by subtracting a constant value from the Summit GEM data and multiplying the Summit GEM data by constant value. The subtraction method led to a minimum $\mathrm{RMSD}_{\text {model-data }}$ value when decreasing the Summit data by $0.78 \mathrm{ng} \cdot \mathrm{m}^{-3}$ (see Table 2 and Figure S3), but the resulting low upper firn values are likely inconsistent with atmospheric GEM data. Better results, both in terms of RMSD $D_{\text {model-data }}$ and Summit upper firn results are obtained by multiplying the Summit GEM data by 0.6 (see Table 2 and lower panels of Figure 4). This acceptable scenario is close to what we obtain using the single site model on NEEM data (Figure 3).With this configuration, GEM peaks around 1970 (1.42-1.96 ng. $\mathrm{m}^{-3}$ ) and would be minimal in 1998 (range 0.94-1.15 ng. $\mathrm{m}^{-3}$ ). GEM levels in the 1940s would be in the 0.55-1.06 ng.m ${ }^{-3}$ range. However the origin of such a difference in GEM data between Summit and NEEM remain to be explained. It is discussed in the following sections.

\section{Comparing the different factors influencing atmospheric GEM signals recorded in the Arctic}

Possible explanations of the differences between NEEM and Summit data are geographical variations, experimental bias, and atmospheric reactivity.

Atmospheric GEM measurements were conducted during different and short time periods and the instrumental configuration differ from one site to another. Atmospheric GEM was $1.38 \pm$ $0.10 \mathrm{ng} \cdot \mathrm{m}^{-3}$ at NEEM 2009 during the field campaign while mean GEM was $1.77 \pm 0.20$ ng. $\mathrm{m}^{-3}$ at Summit in 2006 (Faïn et al., 2009). Brooks et al. (2011) showed average values of $1.31 \pm 0.21 \mathrm{ng} \cdot \mathrm{m}^{-3}$ (13 May - 15 June 2007) and of $1.45 \pm 0.11 \mathrm{ng} \cdot \mathrm{m}^{-3}$ (6 June -17 July 2008) at Summit. Lastly, a recent campaign at Summit from May 31 to August 2009 showed an average GEM concentration of $1.35 \pm 0.13 \mathrm{ng} \cdot \mathrm{m}^{-3}$ (Fain et al, personal communication). As discussed elsewhere (Slemr et al., 2015), GEM measurements made using different Tekran $2537 \mathrm{~A}$ can show an average systematic uncertainty of 10 to $20 \%$. From those partial data set, measurements of GEM of Summit 2006 could be biased high as compared to other studies.

Relatively short-lived atmospheric species such as GEM may display large geographic variations across the Arctic (Helmig et al., 2014). Summit $\left(72^{\circ} 35^{\prime \prime \prime} \mathrm{N}, 38^{\circ} 28^{\prime} \mathrm{W}, 3216 \mathrm{~m}\right.$ altitude) and NEEM $\left(77.45^{\circ} \mathrm{N} 51.06^{\circ} \mathrm{W}, 2452 \mathrm{~m}\right.$ altitude) are $\sim 650 \mathrm{~km}$ distant and their 
1 altitudes differ by more than $700 \mathrm{~m}$, thus the dominant transport pathways of GEM to both

2 sites could differ. Atmospheric transport to Summit is different from High Arctic sites (Alert,

3 Zeppelin) due to its high altitude and remoteness from coastlines. Hirdman et al. (2010)

4 showed that the composition of air at Summit is not representative of the Arctic boundary layer, but rather of the free troposphere. Summit is also strongly influenced by air transported from North America, particularly in summer (Kahl et al., 1997). In contrast, Steen-Larsen et al. (2011) suggested that air mass reaching NEEM originate primarily from the Arctic, the Baffin Bay area (West of Greenland). More recently, continuous monitoring of the surface water vapor isotopic composition at NEEM highlighted the predominance of Arctic air masses and revealed some events where the moisture originates from the evaporation at the Arctic sea-ice margin areas east of Greenland (Steen-Larsen et al., 2013). These finding suggest that the NEEM GEM record is more reflective of Arctic air masses than the Summit record, and differences between the two could be at least partly explained by contrasted airsheds.

As suggested by the absence of seasonal variation of GEM in the upper firn at NEEM (see section 4.1), NEEM site is however different from what is observed at Alert or Zeppelin. NEEM is likely preserved from the influence of AMDEs in springtime and summer GEM evasion from snow or the Arctic Ocean in summer.

This is an important result highlighting the benefit of conducting future studies in high altitude sites in order to understand the GEM background signal of the Arctic troposphere. In particular, year-round GEM measurements at the permanent Summit station during a few years before a new firn air pumping would provide a way to cross check the mean annual atmospheric GEM and concentrations at intermediate depths $(\sim 30-60 \mathrm{~m})$ in the firn. Such measurements would strongly improve our understanding of the link between GEM concentrations at Arctic low-altitude sites and sites representative of free tropospheric conditions.

\section{Implications for the atmospheric GEM history in the Arctic}

As shown on Figure 5, our optimal atmospheric GEM scenario is consistent with both historical anthropogenic $\mathrm{Hg}$ emissions and atmospheric $\mathrm{Hg}$ concentrations simulated by a fully coupled global biogeochemical box model presented in Horowitz et al. (2014).

31 Our optimal scenario show an increase of GEM concentrations during the 1950s and 1960s which can be primarily related to the global rise in $\mathrm{Hg}$ emissions after the Second World War 
1 (Faïn et al., 2009; Streets et al., 2011). At NEEM, GEM concentrations were maximal in 1965-1971 and minimal in 1995-1998. This is consistent with trends of global $\mathrm{Hg}$ releases to air that show maxima of emissions to air in 1970 due to open-air waste burning and a subsequent decrease due to environmental regulations in North America and Europe (Horowitz et al., 2014).

The recent study of an ice-core drilled at NEEM in 2010 revealed a higher net rate of atmospheric deposition of total $\mathrm{Hg}$ (the sum of all oxidized species of $\mathrm{Hg}$, where GEM is therefore not included) from late 1980s and late $1990 \mathrm{~s}$ as compared to the onset of the $20^{\text {th }}$ century (Zheng, 2015). This higher deposition rate is also reflected in the Penny ice cap total Hg record (Zdanowicz et al., 2015) in northern Canada on the west side of the Baffin bay. The coincidence of the GEM minimum at NEEM and the maximum of total $\mathrm{Hg}$ deposition in the ice-cores in the 1990s is striking in a context where global $\mathrm{Hg}$ emissions decreased from 1970 to 2000. Among several potential explanations, the declining sea-ice in this region and a potential promotion of halogen radicals leading to an increased conversion of GEM to depositable $\mathrm{Hg}$ species should be more investigated as proposed by others (Zdanowicz et al., 2015). Although total $\mathrm{Hg}$ and GEM have different chemical properties, life-times and sources, future studies should try to co-investigate those two fractions of atmospheric $\mathrm{Hg}$ in archive records.

After the GEM minimum around 1995-1998, the optimal scenario suggests increasing atmospheric GEM concentrations until 2010 that are consistent with the recent increase of anthropogenic $\mathrm{Hg}$ releases in Asia and global tropospheric $\mathrm{Hg}$ simulations (Horowitz et al., 2014). However, considering the experimental uncertainty and the adequate matching of the upper firn data with constant atmospheric scenarios (see section 4.1 and Figure 2), this optimal scenario should be taken with caution. A constant atmospheric GEM trend for the last 10 years preceding the firn record would be also a plausible alternative that is comprised within the upper and upper bounds of scenarios in Figure 5.

Our result participates in the actual debate regarding recent atmospheric GEM trends. While Horowitz et al. (2014) obtain an increase of atmospheric GEM at a global scale in response to the recent increase of global $\mathrm{Hg}$ releases to air, a decrease of atmospheric GEM is observed over the period 1995 to 2010 at Alert (Cole and Steffen, 2010; Cole et al., 2013). At Zeppelin, 31 atmospheric GEM do not show any clear trend over the period 2000-2009 (Berg et al., 2013; Cole et al., 2013). Using the NEEM record, we cannot firmly conclude on recent GEM trends 
1 in the Arctic. We can solely suggest that the sharp increase of the simulated global

2 tropospheric $\mathrm{Hg}$ using most recent global inventories and $\mathrm{Hg}$ releases to the air (Horowitz et

3 al., 2014) is not as clearly reflected in the GEM record at NEEM. It also suggests that atmospheric GEM trends in the Arctic cannot be solely linked to anthropogenic emissions and that the role of GEM sinks and natural sources have to be more carefully considered. For instance, Chen et al. (2015) suggest a decline of $\mathrm{Hg}$ in the Arctic surface ocean over the period 2000-2009. This decline may lead to decreasing natural GEM emissions from the Arctic surface ocean although the influence of some environmental drivers (such as temperature, sea-ice cover) should be taken into account. An increasing number of studies suggest that sea-ice and the Hg cycle could be linked (Chen et al., 2015; Fisher et al., 2013; Point et al., 2011; Stern et al., 2012; Zdanowicz et al., 2015). Therefore, the role of climatological variables such as the sea-ice extent (coupled with the role of the ocean) should be more deeply investigated in the future given the rapid changes of sea-ice extent observed in the Arctic (Cavalieri and Parkinson, 2012).

Given the lack of current understanding of the $\mathrm{Hg}$ cycling in particular in polar regions, we believe that predictions of future trends of atmospheric GEM concentration and $\mathrm{Hg}$ deposition in those regions in response to changes in anthropogenic sources are highly hypothetical. To answer these questions, an enhanced reinforced network of atmospheric $\mathrm{Hg}$ monitoring is urgently needed in the Arctic and supplementary and long-term observations at high elevation sites are needed.

\section{Acknowledgements}

This research was funded by the IPEV Program NEEM Mercury 1205. We thank our NEEM collaborators for their assistance during the field campaign, especially Mauro Rubino of CSIRO, Australia and the Centre for Ice and Climate, University of Copenhagen, now at the Second University of Naples, Italy, Vas Petrenko of UCSD, USA, now at The University of Rochester, USA, Zoe Courville of USACE, USA and Thomas Blunier (Niels Bohr Institute) for their support. NEEM is directed and organized by the Center of Ice and Climate at the Niels Bohr Institute and US NSF, Office of Polar Programs. It is supported by funding agencies and institutions in Belgium (FNRS-CFB and FWO), Canada (GSC), China, Denmark (FIST), France (IPEV, ANR, CEA and INSU/CNRS), Germany (AWI), Iceland (RannIs), Japan (NIPR), Korea (KOPRI), The Netherlands (NWO/ALW), Sweden (VR), 
1 Switzerland (SNF), United Kingdom (NERC) and the USA (US NSF, Office of Polar 2 Programs). AD acknowledges the Institut Universitaire de France. CSIRO's contribution was 3 supported in part by the Australian Climate Change Science Program, an Australian 4 Government Initiative. We gratefully acknowledge Sandy Steffen, Dorothy Durnford, David 5 G.Streets and Amanda Cole for sharing data and for the useful discussions.

6

7 
Bartels-Rausch, T., Huthwelker, T., Jöri, M., Gäggeler, H.W., Ammann, M., 2008. Interaction of gaseous elemental mercury with snow surfaces: laboratory investigation. Environ. Res. Lett. 3, 045009.

Berg, T., Aspmo, K., Steinnes, E., 2008. Transport of $\mathrm{Hg}$ from Atmospheric mercury depletion events to the mainland of Norway and its possible influence on $\mathrm{Hg}$ deposition. Geophys. Res. Lett. 35, L09802.

Berg, T., Pfaffhuber, K.A., Cole, A.S., Engelsen, O., Steffen, A., 2013. Ten-year trends in atmospheric mercury concentrations, meteorological effects and climate variables at Zeppelin, Ny-Alesund. Atmos. Chem. Phys. 13, 6575-6586.

Boyd, S., Vandenberghe, L., 2004. Convex optimization, Cambridge, New York.

Brooks, S., Moore, C., Lew, D., Lefer, B., Huey, G., Tanner, D., 2011. Temperature and

sunlight controls of mercury oxidation and deposition atop the Greenland ice sheet. Atmos. Chem. Phys. 11, 8295-8306.

Buizert, C., Martinerie, P., Petrenko, V.V., Severinghaus, J.P., Trudinger, C.M., Witrant, E., Rosen, J.L., Orsi, A.J., Rubino, M., Etheridge, D.M., Steele, L.P., Hogan, C., Laube, J.C., Sturges, W.T., Levchenko, V.A., Smith, A.M., Levin, I., Conway, T.J., Dlugokencky, E.J., Lang, P.M., Kawamura, K., Jenk, T.M., White, J.W.C., Sowers, T., Schwander, J., Blunier, T., 2012. Gas transport in firn: multiple-tracer characterisation and model intercomparison for NEEM, Northern Greenland. Atmos. Chem. Phys. 12, 4259-4277.

Cavalieri, D.J., Parkinson, C.L., 2012. Arctic sea ice variability and trends, 1979-2010. The Cryosphere 6, 881-889.

Chen, L., Zhang, Y., Jacob, D.J., Soerensen, A.L., Fisher, J.A., Horowitz, H.M., Corbitt, E.S., Wang, X., 2015. A decline in Arctic Ocean mercury suggested by differences in decadal trends of atmospheric mercury between the Arctic and northern midlatitudes. Geophys. Res. Lett. 42, 6076-6083.

Chen, N.H., Othmer, D.F., 1962. New Generalized Equation for Gas Diffusion Coefficient. J. Chem. Eng. Data 7, 37-41.

Cole, A.S., Steffen, A., 2010. Trends in long-term gaseous mercury observations in the Arctic and effects of temperature and other atmospheric conditions. Atmos. Chem. Phys. 10, 46614672.

Cole, A.S., Steffen, A., Pfaffhuber, K.A., Berg, T., Pilote, M., Poissant, L., Tordon, R., Hung, H., 2013. Ten-year trends of atmospheric mercury in the high Arctic compared to Canadian sub-Arctic and mid-latitude sites. Atmos. Chem. Phys. 13, 1535-1545.

Dastoor, A.P., Durnford, D.A., 2013. Arctic Ocean: Is It a Sink or a Source of Atmospheric Mercury? Environ. Sci. Technol. 48, 1707-1717.

Douglas, T.A., Loseto, L.L., Macdonald, R.W., Outridge, P., Dommergue, A., Poulain, A., Amyot, M., Barkay, T., Berg, T., Chételat, J., Constant, P., Evans, M., Ferrari, C., Gantner, N., Johnson, M.S., Kirk, J., Kroer, N., Larose, C., Lean, D., Nielsen, T.G., Poissant, L., Rognerud, S., Skov, H., Sørensen, S., Wang, F., Wilson, S., Zdanowicz, C.M., 2012. The fate of mercury in Arctic terrestrial and aquatic ecosystems, a review. Environ. Chem. 9, 321-355. 
Durnford, D., Dastoor, A., 2011. The behavior of mercury in the cryosphere: A review of what we know from observations. J. Geophys. Res.-Atmos. 116, D06305.

Durnford, D., Dastoor, A., Figueras-Nieto, D., Ryjkov, A., 2010. Long range transport of mercury to the Arctic and across Canada. Atmos. Chem. Phys. 10, 6063-6086.

Faïn, X., Ferrari, C.P., Dommergue, A., Albert, M., Battle, M., Arnaud, L., Barnola, J.M., Cairns, W., Barbante, C., Boutron, C., 2008. Mercury in the snow and firn at Summit Station, Central Greenland, and implications for the study of past atmospheric mercury levels. Atmos. Chem. Phys. 8, 3441-3457.

Faïn, X., Ferrari, C.P., Dommergue, A., Albert, M.R., Battle, M., Severinghaus, J., Arnaud, L., Barnola, J.-M., Cairns, W., Barbante, C., Boutron, C., 2009. Polar firn air reveals largescale impact of anthropogenic mercury emissions during the 1970s. Proc. Natl. Acad. Sci. U. S. A. 106, 16114-16119.

Fisher, J.A., Jacob, D.J., Soerensen, A.L., Amos, H.M., Corbitt, E.S., Streets, D.G., Wang, Q., Yantosca, R.M., Sunderland, E.M., 2013. Factors driving mercury variability in the Arctic atmosphere and ocean over the past 30 years. Global Biogeochem. Cy. 27, 1226-1235.

Fisher, J.A., Jacob, D.J., Soerensen, A.L., Amos, H.M., Steffen, A., Sunderland, E.M., 2012. Riverine source of Arctic Ocean mercury inferred from atmospheric observations. Nature Geosci. 5, 499-504.

Helmig, D., Petrenko, V., Martinerie, P., Witrant, E., Rockmann, T., Zuiderweg, A., Holzinger, R., Hueber, J., Thompson, C., White, J.W.C., Sturges, W., Baker, A., Blunier, T., Etheridge, D., Rubino, M., Tans, P., 2014. Reconstruction of Northern Hemisphere 19502010 atmospheric non-methane hydrocarbons. Atmos. Chem. Phys. 14, 1463-1483.

Hirdman, D., Sodemann, H., Eckhardt, S., Burkhart, J.F., Jefferson, A., Mefford, T., Quinn, P.K., Sharma, S., Strom, J., Stohl, A., 2010. Source identification of short-lived air pollutants in the Arctic using statistical analysis of measurement data and particle dispersion model output. Atmos. Chem. Phys. 10, 669-693.

Horowitz, H.M., Jacob, D.J., Amos, H.M., Streets, D.G., Sunderland, E.M., 2014. Historical Mercury releases from commercial products: global environmental implications. Environ. Sci. Technol. 48, 10242-10250.

Kahl, J.D.W., Martinez, D.A., Kuhns, H., Davidson, C.I., Jaffrezo, J.-L., Harris, J.M., 1997. Air mass trajectories to Summit, Greenland: A 44-year climatology and some episodic events. J Geophys Res-Oceans 102, 26861-26875.

Lalonde, J.D., Poulain, A.J., Amyot, M., 2002. The role of mercury redox reactions in snow on snow-to-air mercury transfer. Environ. Sci. Technol. 36, 174-178.

Larose, C., Dommergue, A., Marusczak, N., Coves, J., Ferrari, C.P., Schneider, D., 2011. Bioavailable Mercury Cycling in Polar Snowpacks. Environ. Sci. Technol. 45, 2150-2156.

Laube, J.C., Newland, M.J., Hogan, C., Brenninkmeijer, C.A.M., Fraser, P.J., Martinerie, P., Oram, D.E., Reeves, C.E., Rockmann, T., Schwander, J., Witrant, E., Sturges, W.T., 2014. Newly detected ozone-depleting substances in the atmosphere. Nature Geosci. 7, 266-269.

Lugg, G.A., 1968. Diffusion coefficients of some organic and other vapors in air. Anal. Chem. 40, 1072-\&.

Massman, W.J., 1998. A review of the molecular diffusivities of $\mathrm{H}_{2} \mathrm{O}, \mathrm{CO}_{2}, \mathrm{CH}_{4}, \mathrm{CO}, \mathrm{O}_{3}$, $\mathrm{SO}_{2}, \mathrm{NH}_{3}, \mathrm{~N}_{2} \mathrm{O}, \mathrm{NO}$, and $\mathrm{NO}_{2}$ in air, $\mathrm{O}_{2}$ and $\mathrm{N}_{2}$ near STP. Atmos. Environ. 32, 1111-1127. 
Massman, W.J., 1999. Molecular diffusivities of $\mathrm{Hg}$ vapor in air, $\mathrm{O}_{2}$ and $\mathrm{N}_{2}$ near STP and the kinematic viscosity and thermal diffusivity of air near STP. Atmos. Environ. 33, 453-457.

Matsunaga, N., Hori, M., Nagashima, A., 1998. Diffusion coefficients of global warming gases into air and its component gases. High Temp. - High Pressures 30, 77-83.

Petrenko, V.V., Martinerie, P., Novelli, P., Etheridge, D.M., Levin, I., Wang, Z., Blunier, T., Chappellaz, J., Kaiser, J., Lang, P., Steele, L.P., Hammer, S., Mak, J., Langenfelds, R.L., Schwander, J., Severinghaus, J.P., Witrant, E., Petron, G., Battle, M.O., Forster, G., Sturges, W.T., Lamarque, J.F., Steffen, K., White, J.W.C., 2013. A 60 yr record of atmospheric carbon monoxide reconstructed from Greenland firn air. Atmos. Chem. Phys. 13, 7567-7585.

Point, D., Sonke, J.E., Day, R.D., Roseneau, D.G., Hobson, K.A., Vander Pol, S.S., Moors, A.J., Pugh, R.S., Donard, O.F.X., Becker, P.R., 2011. Methylmercury photodegradation influenced by sea-ice cover in Arctic marine ecosystems. Nature Geosci. 4, 188-194.

Poulain, A.J., Lalonde, J.D., Amyot, M., Shead, J.A., Raofie, F., Ariya, P.A., 2004. Redox transformations of mercury in an Arctic snowpack at springtime. Atmos. Environ. 38, 67636774.

Rommelaere, V., Arnaud, L., Barnola, J.M., 1997. Reconstructing recent atmospheric trace gas concentrations from polar firn and bubbly ice data by inverse methods. J. Geophys. Res.Atmos. 102, 30069-30083.

Schwander, J., Barnola, J.M., Andrie, C., Leuenberger, M., Ludin, A., Raynaud, D., Stauffer, B., 1993. The age of the air in the firn and the ice at Summit, Greenland. J. Geophys. Res.Atmos. 98, 2831-2838.

Slemr, F., Angot, H., Dommergue, A., Magand, O., Barret, M., Weigelt, A., Ebinghaus, R., Brunke, E.G., Pfaffhuber, K.A., Edwards, G., Howard, D., Powell, J., Keywood, M., Wang, F., 2015. Comparison of mercury concentrations measured at several sites in the Southern Hemisphere. Atmos. Chem. Phys. 15, 3125-3133.

Soerensen, A.L., Jacob, D.J., Streets, D.G., Witt, M.L.I., Ebinghaus, R., Mason, R.P., Andersson, M., Sunderland, E.M., 2012. Multi-decadal decline of mercury in the North Atlantic atmosphere explained by changing subsurface seawater concentrations. Geophys. Res. Lett. 39.

Steen-Larsen, H.C., Johnsen, S.J., Masson-Delmotte, V., Stenni, B., Risi, C., Sodemann, H., Balslev-Clausen, D., Blunier, T., Dahl-Jensen, D., Ellehøj, M.D., Falourd, S., Grindsted, A., Gkinis, V., Jouzel, J., Popp, T., Sheldon, S., Simonsen, S.B., Sjolte, J., Steffensen, J.P., Sperlich, P., Sveinbjörnsdóttir, A.E., Vinther, B.M., White, J.W.C., 2013. Continuous monitoring of summer surface water vapor isotopic composition above the Greenland Ice Sheet. Atmos. Chem. Phys. 13, 4815-4828.

Steen-Larsen, H.C., Masson-Delmotte, V., Sjolte, J., Johnsen, S.J., Vinther, B.M., Bréon, F.M., Clausen, H.B., Dahl-Jensen, D., Falourd, S., Fettweis, X., Gallée, H., Jouzel, J., Kageyama, M., Lerche, H., Minster, B., Picard, G., Punge, H.J., Risi, C., Salas, D., Schwander, J., Steffen, K., Sveinbjörnsdóttir, A.E., Svensson, A., White, J., 2011. Understanding the climatic signal in the water stable isotope records from the NEEM shallow firn/ice cores in northwest Greenland. J. Geophys. Res.-Atm. 116, D06108.

Steffen, A., Douglas, T., Amyot, M., Ariya, P., Aspmo, K., Berg, T., Bottenheim, J., Brooks, S., Cobbett, F., Dastoor, A., Dommergue, A., Ebinghaus, R., Ferrari, C., Gardfeldt, K., Goodsite, M.E., Lean, D., Poulain, A.J., Scherz, C., Skov, H., Sommar, J., Temme, C., 2008. 
1 A synthesis of atmospheric mercury depletion event chemistry in the atmosphere and snow.

2 Atmos. Chem. Phys. 8, 1445-1482.

3 Stern, G.A., Macdonald, R.W., Outridge, P.M., Wilson, S., Chetelat, J., Cole, A., Hintelmann, 4 H., Loseto, L.L., Steffen, A., Wang, F.Y., Zdanowicz, C., 2012. How does climate change 5 influence arctic mercury? Sci. Total Environ. 414, 22-42.

6 Streets, D.G., Devane, M.K., Lu, Z.F., Bond, T.C., Sunderland, E.M., Jacob, D.J., 2011. All7 Time Releases of Mercury to the Atmosphere from Human Activities. Environ. Sci. Technol. 8 45, 10485-10491.

9 Wang, Z., Chappellaz, J., Martinerie, P., Park, K., Petrenko, V., Witrant, E., Emmons, L.K., 10 Blunier, T., Brenninkmeijer, C.A.M., Mak, J.E., 2012. The isotopic record of Northern 11 Hemisphere atmospheric carbon monoxide since 1950: implications for the CO budget. 12 Atmos. Chem. Phys. 12, 4365-4377.

13 Witrant, E., Martinerie, P., 2013. Input Estimation from Sparse Measurements in LPV Systems and Isotopic Ratios in Polar Firns, in: Witrant, E., Martinez-Molina, J.J., Lovera, M., Sename, O., Dugard, L. (Eds.), 5th IFAC Symposium on System Structure and Control, WTC, Grenoble, France, pp. 659-664.

Witrant, E., Martinerie, P., Hogan, C., Laube, J.C., Kawamura, K., Capron, E., Montzka, S.A., Dlugokencky, E.J., Etheridge, D., Blunier, T., Sturges, W.T., 2012. A new multi-gas constrained model of trace gas non-homogeneous transport in firn: evaluation and behaviour at eleven polar sites. Atmos. Chem. Phys. 12, 11465-11483.

Zdanowicz, C., Kruemmel, E., Lean, D., Poulain, A., Kinnard, C., Yumvihoze, E., Chen, J., Hintelmann, H., 2015. Pre-industrial and recent (1970-2010) atmospheric deposition of sulfate and mercury in snow on southern Baffin Island, Arctic Canada. Sci. Total Environ. 509-510, 104-114.

Zheng, J., 2015. Archives of total mercury reconstructed with ice and snow from Greenland and the Canadian High Arctic. Sci. Total Environ. 509-510, 133-144.

Zuiderweg, A., Holzinger, R., Martinerie, P., Schneider, R., Kaiser, J., Witrant, E., Etheridge, D., Petrenko, V., Blunier, T., Rockmann, T., 2013. Extreme C-13 depletion of CCl2F2 in firn air samples from NEEM, Greenland. Atmos. Chem. Phys. 13, 599-609. 
Table 1. Estimated mean age of GEM in firn air at Summit and NEEM for various depths

\begin{tabular}{c|c|c|c|c|c}
\hline \multicolumn{3}{|c|}{ Summit } & \multicolumn{3}{c}{ NEEM 2009 } \\
\hline Depth (m) & Mean Year & Age width & Depth $(\mathrm{m})$ & Mean year & Age width \\
\hline 0 & 2006.4 & 0 & 0 & 2009.5 & 0 \\
15 & 2004.8 & 2.4 & 20 & 2008.0 & 2.3 \\
25 & 2003.4 & 5.2 & 30 & 2007.0 & 4.1 \\
30 & 2002.7 & 6.3 & 40 & 2005.8 & 5.7 \\
40 & 2001.3 & 8.2 & 50 & 2004.5 & 7.1 \\
50 & 1999.9 & 9.6 & 60 & 2002.0 & 9.8 \\
58 & 1998.7 & 10.6 & 62 & 2000.4 & 11.6 \\
63 & 1997.8 & 11.3 & 64 & 1994.0 & 18.5 \\
66 & 1997.0 & 12 & 67 & 1981.1 & 26.9 \\
70 & 1994.0 & 15 & 69 & 1973.4 & 29.2 \\
72 & 1987.2 & 20.8 & 72 & 1959.6 & 30 \\
76 & 1972.8 & 25.5 & 73 & 1955.1 & 30.2 \\
78 & 1965.1 & 27.1 & 74 & 1950.6 & 30.5 \\
79.6 & 1959.6 & 27.7 & 75 & 1946.3 & 30.7 \\
& & & 76 & 1942.1 & 30.8 \\
\hline
\end{tabular}


Table 2. Sensitivity of multi-site simulations to the assumed difference in atmospheric GEM between Summit and NEEM. The average mismatch between inverse model results and firn data (expressed as root mean square deviations in $n g . \mathrm{m}^{-3}$ ) is presented for various combinations. The RMSD for individual GEM measurements is $0.10 \mathrm{ng} \cdot \mathrm{m}^{-3}$.

\begin{tabular}{c|c|l|c}
\hline Multi-site simulations & RMSD & Multi-site simulations & RMSD \\
\hline NEEM + $1 *$ Summit & 0.35 & NEEM + Summit-0 & 0.35 \\
NEEM + 0.8*Summit & 0.19 & NEEM + Summit-0.38 & 0.22 \\
NEEM + 0.7*Summit & 0.13 & NEEM + Summit-0.58 & 0.17 \\
NEEM + 0.6*Summit & 0.10 & NEEM + Summit-0.78 & 0.15 \\
NEEM + 0.5*Summit & 0.14 & NEEM + Summit-0.98 & 0.17 \\
\hline
\end{tabular}




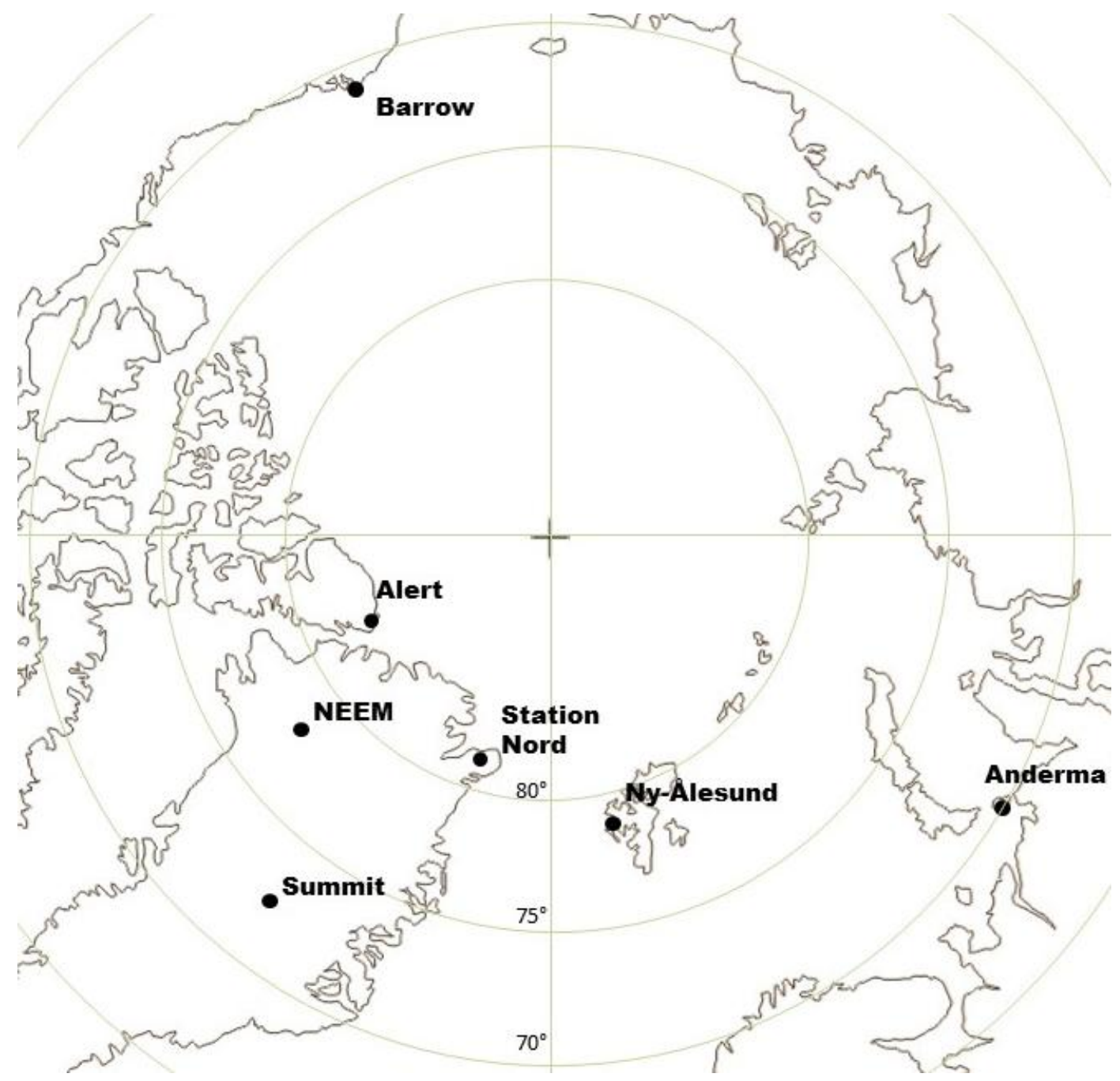

Figure 1: Map of the Arctic showing firn air measurements sites of NEEM and Summit. Measurement sites, where direct atmospheric GEM monitoring data are available, are also shown. 


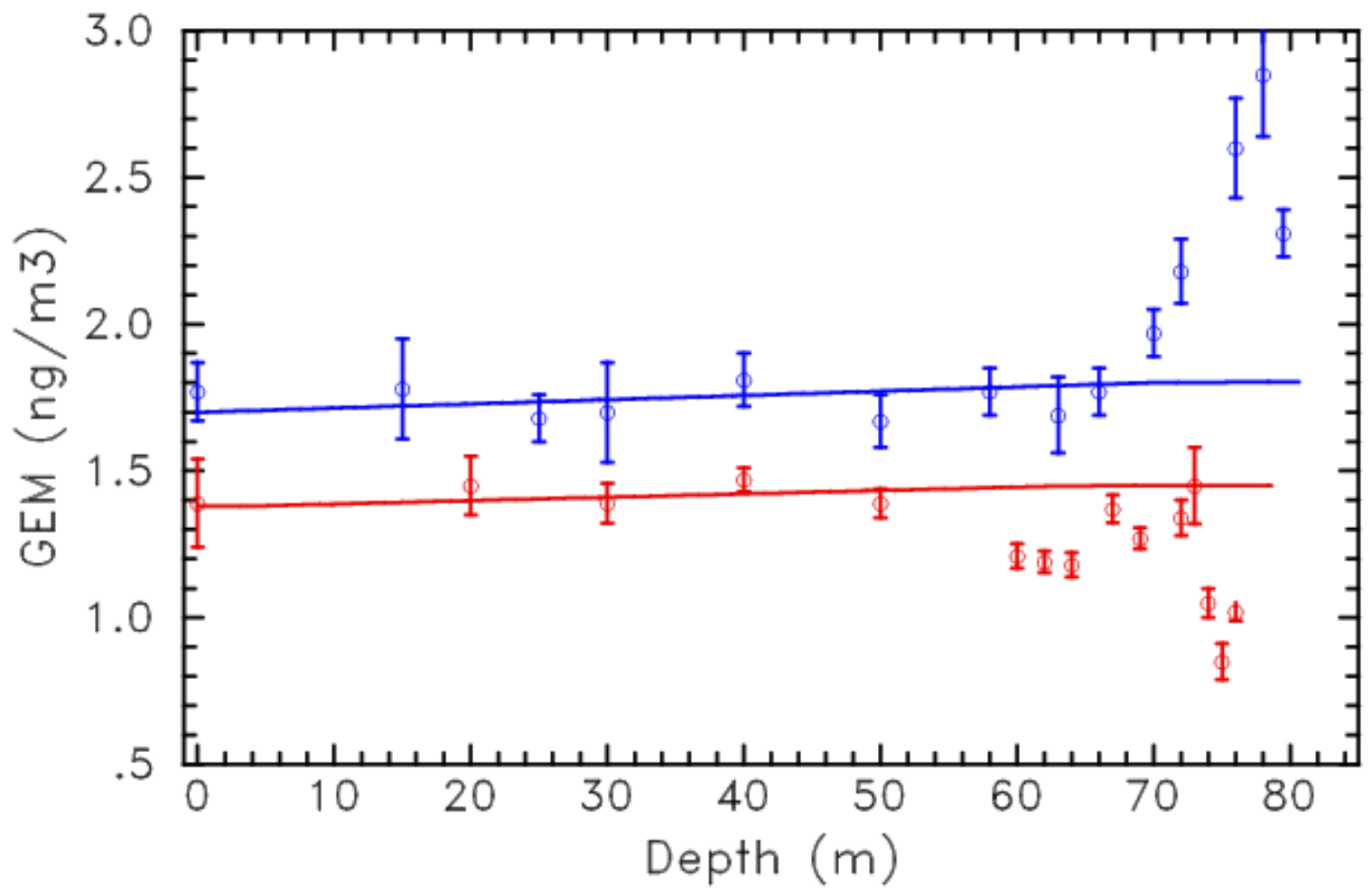

Figure 2: Mean GEM concentrations $( \pm \sigma)$ measured in the firn at NEEM (red) and at Summit (blue). Summit data are from Faïn et al. (2009). Mean surface atmospheric GEM levels are also plotted. Constant atmospheric GEM levels of $1.7 \mathrm{ng} . \mathrm{m}^{-3}$ and $1.38 \mathrm{ng} . \mathrm{m}^{-3}$ are used to test the effect of GEM gravitational settling at Summit and NEEM respectively. In this case, GEM diffuses via gravity only and the corresponding GEM firn profiles that would be measured are shown by the blue and red line for Summit and NEEM respectively. These lines fit the firn measurements down to $\sim 50 \mathrm{~m}$. It illustrates the fact that GEM concentrations have stayed roughly constant (given the experimental uncertainty) for the last decade preceding the firn pumping experiment. 

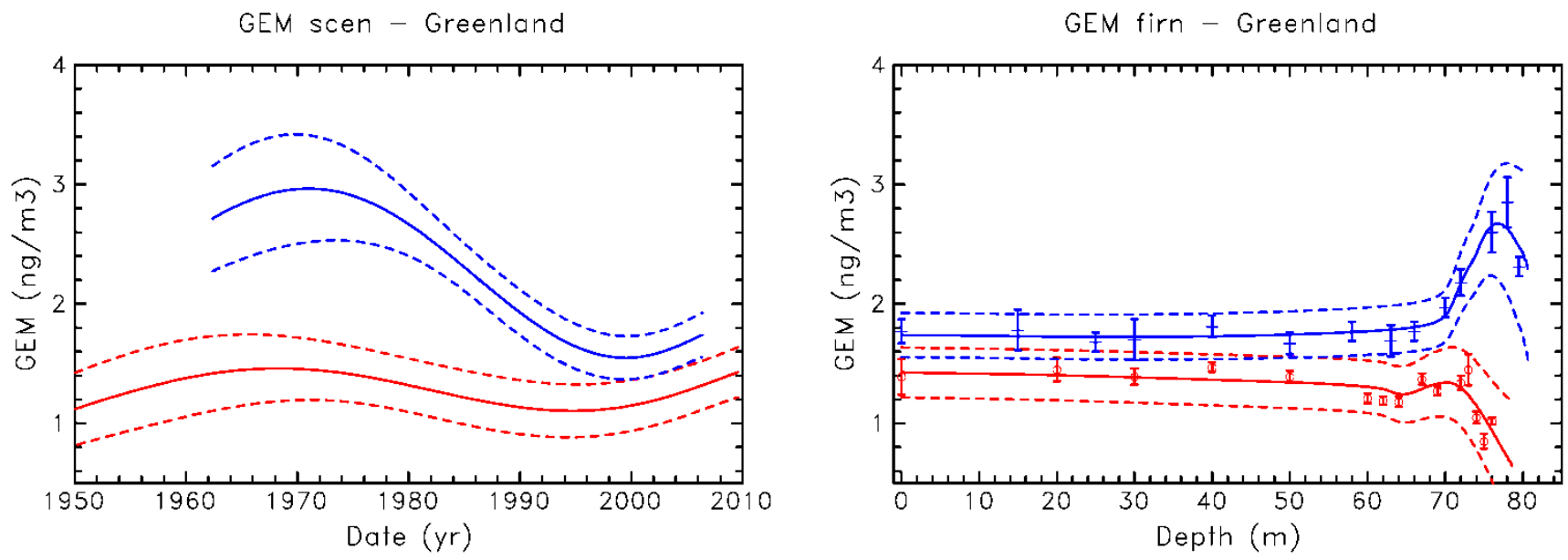

Figure 3: Left panel: scenarios of reconstructed atmospheric GEM using single site model at NEEM (red) and Summit (blue). The solid lines show the optimal scenario with its uncertainty envelopes as dashed lines. Other scenarios using different regularization terms are shown on supplementary figure S2. Right panel: GEM concentrations in firn obtained by the model using the corresponding scenarios of the left panels. Same color codes apply. The GEM firn air measurements are also reported. 
Figure 4: Upper panels: optimal GEM scenarios using multi-site estimation. Left panels: best estimate time trends (continuous line) and uncertainty envelopes (dashed lines). Right panels: concentrations in Summit (blue line) and NEEM (red line) firns calculated with the optimal scenarios, compared with the measurements (circles with error bars). Optimal solutions using equal weights are used for both sites. Lower panels: same figure using a rescaling (multiplying factor) of 0.6 for Summit data.
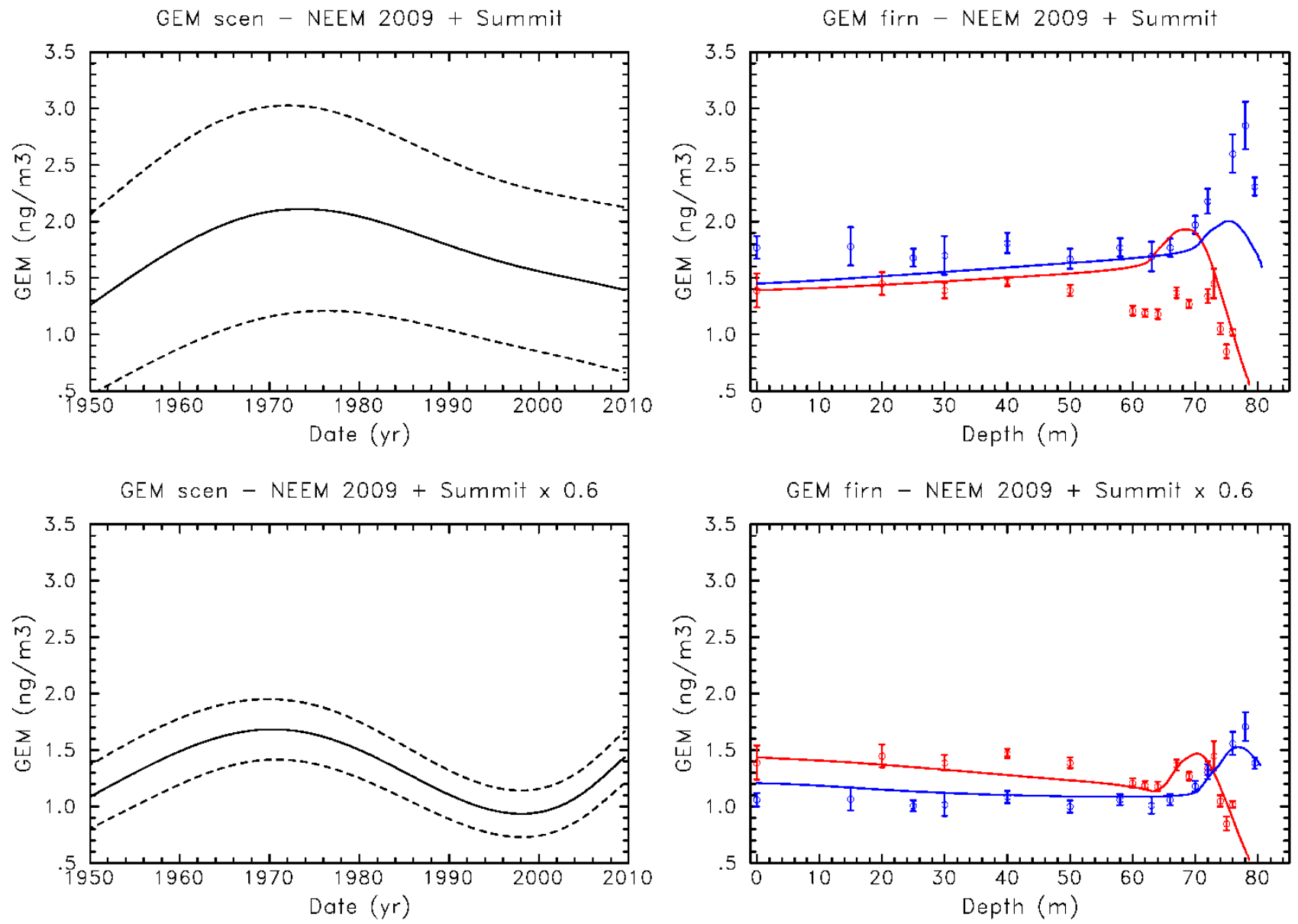




2

3 Figure 5: GEM trends as reconstructed by the firn air record. The black line with the two 4 dash lines represent the optimal scenario and its envelope obtained using NEEM data. The 5 gray line shows the simulated global tropospheric $\mathrm{Hg}$ signal and the bold black line represents 6 the history of global $\mathrm{Hg}$ releases to air. These data are extracted from Horowitz et al. (2014). 